\title{
A Novel Escherichia coli Lipid A Mutant That Produces an Antiinflammatory Lipopolysaccharide
}

\author{
John E. Somerville, Jr., Linda Cassiano, Brian Bainbridge, Mark D. Cunningham, and Richard P. Darveau \\ Inflammation Department, Bristol-Myers Squibb Pharmaceutical Research Institute, Seattle, Washington 98121
}

\begin{abstract}
A unique screen was used to identify mutations in Escherichia coli lipid A biosynthesis that result in a decreased ability to stimulate E-selectin expression by human endothelial cells. A mutation was identified in the $m s b \mathrm{~B}$ gene of $E$. coli that resulted in lipopolysaccharide (LPS) that lacks the myristoyl fatty acid moiety of the lipid A. Unlike all previously reported lipid A mutants, the $m s b \mathrm{~B}$ mutant was not conditionally lethal for growth. Viable cells or purified LPS from an $m s b \mathrm{~B}$ mutant had a 1000-10,000-fold reduction in the ability to stimulate E-selectin production by human endothelial cells and TNF $\alpha$ production by adherent monocytes. The cloned $m s b \mathrm{~B}$ gene was able to functionally complement the $m s b \mathrm{~B}$ mutant, restoring both the LPS to its native composition and the ability of the strain to stimulate immune cells. Nonmyristoylated LPS acted as an antagonist for E-selectin expression when mixed with LPS obtained from the parental strain. These studies demonstrate a significant role for the myristate component of LPS in immune cell activation and antagonism. In addition, the $m s b \mathrm{~B}$ mutant allowed us to directly examine the crucial role that the lipid A structure plays when viable bacteria are presented to host defense cells. (J. Clin. Invest. 1996. 97:359-365.) Key words: sepsis • endotoxins - gram-negative bacterial infections $\bullet$ cell adhesion $\bullet$ bacterial genes
\end{abstract}

\section{Introduction}

The endotoxic lipopolysaccharide (LPS) of many gram negative bacteria can act as a potent stimulator of the immune system and as a pathogenic factor in septic shock. In humans, very low concentrations of this endotoxin of the gram negative bacterial cell wall can increase expression of cellular adhesion molecules and induce cytokine secretion (1). These and other effects of LPS on the human immune system are believed to be a host protective mechanism to insure that the numerous commensal gram negative bacteria are properly contained within the body. However, in certain immuno-compromised individuals, LPS can have a lethal effect due to its excessive activation of the inflammatory system (2).

Studies examining the role of LPS in the induction of inflammation have used purified LPS that has been partially de-

Address correspondence to Richard P. Darveau, Inflammation Department, Bristol-Myers Squibb Pharmaceutical Research Institute, 3005 First Avenue, Seattle, WA 98121. Phone: 206-727-3511; FAX: 206- 727-3602.

Received for publication 1 August 1995 and accepted in revised form 5 October 1995.

J. Clin. Invest.

(C) The American Society for Clinical Investigation, Inc.

0021-9738/96/01/359/07 \$2.00

Volume 97, Number 2, January 1996, 359-365 graded, purified biosynthetic intermediates, or chemically synthesized analogues. These studies have demonstrated that the lipid A portion of the LPS molecule is responsible for the majority of immunomodulating activity of LPS $(3,4)$. For example, treatment of purified LPS with a neutrophil enzyme, acyloxyacyl hydrolase (AOAH), results in the removal of the "piggyback" acyloxyacyl myristate and laurate fatty acids. Such deacylated LPS can no longer stimulate neutrophil adhesion (4). Attempts to analyze the role of lipid A in viable bacterial interactions with cells of the human immune system have been hampered however, by the fact that all lipid A biosynthetic mutants so far identified in E. coli are conditionally lethal (temperature sensitive) (5). This has precluded studies of altered forms of LPS within the context of viable bacterial cells, where the LPS can be presented to immune cells from its more "native" environment.

We report here the isolation of a mutation in E. coli lipid A biosynthesis that results in a strain that is not temperature sensitive for growth and which has a diminished ability to stimulate cells of the host immune system. Our screen was based upon the fact that at least one of two acyloxyacyl fatty acids located in the lipid A are required for activation of neutrophil adhesion and that these fatty acids are added late in the biosynthetic pathway $(5,6)$. We predicted that LPS missing one or both of these fatty acids would be a poor activator of E-selectin expression in a fashion analogous to the lack of stimulation seen with certain bacteria associated with chronic infections (7). The LPS isolated from this mutant is devoid of myristic acid, is affected in its ability to stimulate human imune cells in vitro, and can act as an antagonist.

\section{Methods}

Bacterial strains, plasmids, and phage. The E. coli strain $\mathrm{JM} 83 \mathrm{~F}^{-}$ara $\Delta$ (lac-pro $\mathrm{AB}) r p s \mathrm{~L}\left(\mathrm{Str}^{\mathrm{r}}\right)[\phi 80 \mathrm{~d}$ lac $\Delta$ (lacZ) M15] was the K-12 strain selected for mutagenesis in this study (8). E. coli JM109 was used for all plasmid propagation (8). E. coli Q1 (9) was used for propagation and titration of $\lambda 467$ phage (9). E. coli A645 was obtained from the American Type Culture Collection (Rockville, MD) and was used as a control strain for validation of antibiotic susceptibility testing. The vector plasmid pUC18 was used for all of the cloning described in this study (8). Plasmid pRZ102 carries the transposon Tn5 in a colE1 vector and was used as a hybridization probe for Tn5 sequences (10).

Bacterial media, growth conditions, and antibiotic susceptibility testing. E. coli was routinely grown in LB media (11) at 30 or $37^{\circ} \mathrm{C}$ as indicated in the text. When needed as a selective agent, ampicillin was added at a final concentration of $100 \mu \mathrm{g} / \mathrm{ml}$ and kanamycin sulfate at a final concentration of $75 \mu \mathrm{g} / \mathrm{ml}$. Minimum inhibitory concentrations were done using the microbroth dilution method in media that contained physiological levels of divalent cations as described (12). Precise enumeration of viable cell counts ( $\mathrm{cfu} / \mathrm{ml})$ during growth studies and for stimulation experiments were determined as described earlier (13).

Mutagenesis of E. coli JM83 with transposon Tn5. JM83 was grown to late-log phase in LB broth supplemented with $0.2 \%$ maltose. The cells were isolated by centrifugation and were suspended in 
$1 / 2 \mathrm{vol}$ of $10 \mathrm{mM} \mathrm{MgSO} \cdot \cdot 7 \mathrm{H}_{2} \mathrm{O}, 10 \mathrm{mM}$ Tris $\mathrm{pH}$ 7.5. Serial dilutions of a $\lambda 467$ phage stock $\left(7 \times 10^{10} \mathrm{pfu} / \mathrm{ml}\right)$ were mixed with $0.1-\mathrm{ml}$ aliquots of JM83 cells and the mixture was allowed to incubate at room temperature for $5 \mathrm{~min}$. Next, $0.9 \mathrm{ml}$ of LB broth was added to the infected cells and the culture was incubated for $30 \mathrm{~min}$ at $37^{\circ} \mathrm{C}$ with shaking, to allow Tn5 transposition and expression of the kanamycin resistance marker. Cells from each culture were then concentrated by centrifugation, suspended in $0.1 \mathrm{ml}$ of LB broth and spread onto LB agar plates containing kanamycin. After growth overnight at $37^{\circ} \mathrm{C}$, Tn5 mutants were individually picked from plates infected at an MOI of $<1$ into 96-well, low protein binding, microtiter plates (Corning Costar, Cambridge, MA) that contained $0.15 \mathrm{ml}$ of LB broth with kanamycin. After overnight growth at $37^{\circ} \mathrm{C}$, without shaking, the microtiter plates were centrifuged to pellet the cells. The cells were resuspended in fresh LB broth containing $15 \%$ glycerol, then the plates were frozen on dry ice and stored at $-70^{\circ} \mathrm{C}$.

Stimulation of human umbilical vein endothelial cells (HUVEC) and detection of E-selectin. HUVEC cells were purchased from Clonetics (San Diego, CA) and were propagated in HUVEC growth media as described earlier (7). Stimulation assays utilized cells passed no more than four times. The E-selectin stimulation ELISA assay has been described in detail earlier (7). For this study, stimulation assays were carried out in the presence of $5 \%$ pooled normal human serum (Gemini Bioproducts, Calabasas, CA) or 5\% human albumin (Immuno-US Inc., Rochester, MI) when serum free conditions were desired. The anti-E-selectin antibody BBA1 was purchased from $\mathrm{R}$ and D Systems, (Minneapolis, $\mathrm{MN}$ ) and the $\mathrm{F}\left(\mathrm{ab}^{\prime}\right) 2$ goat anti-mouse IgG specific HRP-conjugated second step detection antibody was purchased from Jackson Immunoresearch Labs (West Grove, PA).

Screening of E. coli mutants for loss of ability to stimulate HUVEC cells. Nonmutagenized JM83 cells grown in microtiter plates were used to determine the appropriate dilutions necessary to observe serum dependent stimulation of E-selectin on HUVEC cells. Dilutions of cells in stimulation media (7) without serum demonstrated serumindependent stimulation at high cell numbers. Thus, a dilution that gave an absorption value in the E-selectin assay (7) of between 0.4 and 0.8 in the presence of $5 \%$ normal human serum, but a serum-free value equal to background, was used. Each microtiter plate contained controls consisting of non-stimulated HUVEC cells, wells stimulated with $\mathrm{TNF} \alpha$, and wells stimulated with the non-mutagenized JM83 strain.

Any mutants identified in the preliminary screen above were then subjected to a secondary screen. This consisted of growing cultures of prospective mutants and the JM83 control overnight in LB broth at $37^{\circ} \mathrm{C}$ with shaking. The culture densities were measured and adjusted using LB broth to an $\mathrm{A}_{660}$ value that correlated with $1 \times 10^{8} \mathrm{cfu} / \mathrm{ml}$. For JM83, BMS50F5 and BMS67C12 the experimentally derived conversion factor for growth in LB broth at $30^{\circ} \mathrm{C}$ was $4 \times 10^{8} \mathrm{cfu} / \mathrm{ml}$ equal to an $\mathrm{A}_{660}$ value of 1.0. Serial 10-fold dilutions of the cultures were then made in stimulation media and the samples placed onto HUVEC cells to measure stimulation of E-selectin.

LPS isolation and analysis of fatty acids. For rapid purification of LPS and analysis of fatty acids, $10 \mathrm{mg}$ of lyophilized cells were extracted three times with $45 \%$ phenol at $70^{\circ} \mathrm{C}$ and the cooled aqueous layers recovered by centrifugation. After extraction with diethyl ether, the aqueous phase was evaporated to dryness under a flow of nitrogen gas at $45^{\circ} \mathrm{C}$. For large scale isolation of high purity LPS, the phenol-water method of Westphal and Jann was used (14).

To determine whole cell phospholipid composition, 50-mg aliquots of lyophilyzed cells were extracted as described earlier (15) before derivatization and analysis. For whole cell fatty acid analysis, 5-mg aliquots of lyophilyzed cells were derivatized and analyzed as described below.

LPS fatty acids, whole cell phospholipids, and whole cell fatty acids were derivatized to fatty acid methyl esters by methanolysis in $2 \mathrm{M}$ methanolic $\mathrm{HCl}$ at $90^{\circ} \mathrm{C}$ for $18 \mathrm{~h}$ with the addition of pentadecanoic acid as an internal standard (16). After the addition of an equal volume of saturated $\mathrm{NaCl}$ solution, the methyl esters were extracted with hexane and analyzed by gas chromatography. Analysis used a $50 \mathrm{~m} \times 0.25 \mathrm{~mm}$ HP-1 capillary column on a Hewlett-Packard 5890 gas chromatograph with a programed temperature ramp from 90 to $225^{\circ} \mathrm{C}$. Trifluoroacetic acid derivatization and characterization of LPS carbohydrates was done as described earlier (16) and LPS phosphate analysis was done as described by Ames (17). Limulus amebocyte lysate (LAL) testing was done using a kinetic assay in an automated microplate reader according to the manufacturer's instructions (Endosafe, Charleston, SC).

Recombinant DNA methods. Total DNA was isolated as described earlier (18). Restriction endonucleases and DNA modification enzymes were from commercial sources and used according to the manufacturer's instructions. Blotting of DNA to nitrocellulose was done using a modification of the Southern blotting technique (11). Supercoiled plasmid DNA to be labeled for hybridization was first treated with an ATP-dependent DNase (Plasmid-Safe; Epicentre Technologies, Madison, WI) to eliminate any E. coli chromosomal DNA contamination. For detecting Tn5 insertions, the plasmid pRZ102 was labeled using a digoxigenin random primed labeling and detection system (Boehringer Mannheim Corp., Indianapolis, IN). Dideoxy DNA sequencing was done by a central core facility using a primer (ATGGAAGTCAGATCCTGG) designed to bind within the Tn5 insertion sequences and allow sequencing in an outward direction from the Tn5. Cloning of the intact $m s b \mathrm{~B}$ gene was successfully accomplished using the oligonucleotides TCGATCGGATCCCCACATCCGGCCTACAGTTCAATG and TCGTCGCGAATTCCTGGCG in a polymerase chain reaction (PCR) with an anealing temperature of $50^{\circ} \mathrm{C}, 2.5 \mathrm{mM} \mathrm{MgCl}_{2}$ and 35 amplification cycles.

Isolation and stimulation of adherent monocytes from normal human blood. Adherent monocytes were isolated from the whole blood of individuals randomly selected from a population of normal human donors. Whole heparinized blood from an individual donor was diluted with one volume of RPMI 1640 medium (GIBCO BRL, Gaithersburg, MD) and overlayered onto Lymphocyte Separation Medium (Organon Teknika Corp., Durham, NC). The gradient was centrifuged at $500 \times g$ for $30 \mathrm{~min}$ at room temperature. The lymphocyte layer was removed and the lymphocytes diluted with 1 vol of RPMI 1640. The cells were pelleted and washed once more in RPMI 1640 then resuspended in a small volume of RPMI 1640 containing $5 \%$ fetal calf serum. After counting and dilution to $5 \times 10^{6}$ cells $/ \mathrm{ml}, 1 \mathrm{ml}$ aliquots were added to each well of 24 -well tissue culture plates. Cells were allowed to adhere for $1 \mathrm{~h}$ at $37^{\circ} \mathrm{C}$, then the monolayers were washed three times with serum free RPMI 1640. Typically, adherent cells represented $10 \%$ of the lymphocyte population. After washing, RPMI 1640 medium containing 5\% normal human serum and the various stimulatory additives was added. LPS stocks were sonicated in a bath sonicator immediately prior to dilution and use in each experiment. After $4 \mathrm{~h}$ of stimulation, the culture supernatants were harvested and assayed for the presence of TNF $\alpha$ using a human TNF $\alpha$ specific ELISA assay (Amersham Corp., Arlington Heights, IL).

Blocking of CD14 mediated immune stimulation. MY4 is an antiCD14 specific antibody that has been previously shown to block immune stimulation via CD14-dependent pathways (19-21). MY4 (Coulter Immunology, Hialeah, FL) was added at varying concentrations to stimulation medium containing $5 \%$ normal human serum and incubated for $1 \mathrm{~h}$ at $37^{\circ} \mathrm{C}$. Next, LPS $(5 \mathrm{ng} / \mathrm{ml})$ or nonmyristoylated LPS (nmLPS) $(500 \mathrm{ng} / \mathrm{ml})$ were then added to the stimulation media and $100-\mu l$ aliquots of the mixtures were used in the HUVEC based E-selectin assay described above (7). Blocking stimulation of adherent monocytes was done by incubating isolated adherent monocytes with the MY4 antibody diluted in serum free stimulation medium for $1 \mathrm{~h}$ at $37^{\circ} \mathrm{C}$ before the addition of the LPS and $5 \%$ normal human serum. For adherent monocytes, LPS was used at $10 \mathrm{ng} / \mathrm{ml}$ and nmLPS was used at $100 \mathrm{ng} / \mathrm{ml}$. After $4 \mathrm{~h}$ of stimulation the level of TNF $\alpha$ in the culture supernatants was determined as described above.

Antagonism effects of nmLPS on HUVEC stimulation. Various dilutions of nmLPS were added to a constant concentration of LPS isolated from JM83. LPS stocks were sonicated in a bath sonicator 


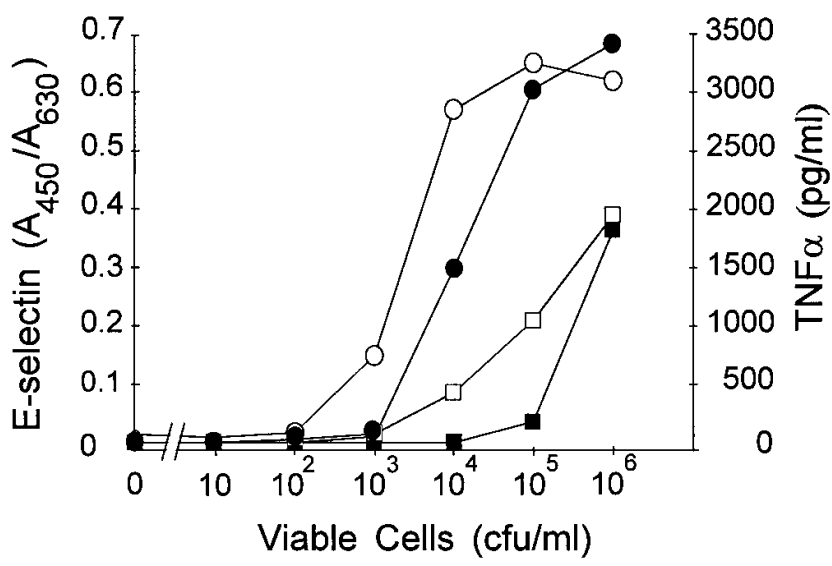

Figure 1. E-selectin expression and TNF $\alpha$ production induced by viable whole cells. Viable whole cells of JM83 $(\bullet, \bigcirc)$ and BMS67C12 $(\square, \square)$ were grown in LB media to stationary phase. The cells were pelleted, suspended in PBS, and the densities were adjusted to $1 \times 10^{8}$ $\mathrm{cfu} / \mathrm{ml}$. Dilutions of the cells in stimulation media that contained $5 \%$ NHS were used to stimulate either HUVEC for $4 \mathrm{~h}$ or adherent human monocytes for $4 \mathrm{~h}$. After stimulation E-selectin expression (solid symbols) or TNF $\alpha$ (open symbols) production was measured. Bacterial cell titers were adjusted and confirmed as described in Methods. E-selectin data shown is a representative of six separate experiments performed in duplicate and TNF $\alpha$ data is a representative of three experiments performed in duplicate.

immediately before dilution and use in each experiment. The mixtures of LPSs were then added to stimulation media containing $5 \%$ NHS and placed onto HUVEC. After $4 \mathrm{~h}$ of stimulation, the cells were assayed for E-selectin expression as described above.

\section{Results}

Isolation of E. coli mutants that have a reduced ability to stimulate human immune cells. We predicted that a mutation at one of the last acylation steps in the LPS biosynthetic pathway would alter the ability of $E$. coli to stimulate E-selectin expression by endothelial cells, but we were unsure of the strength of the resulting phenotype. We therefore mutagenized an E. coli $\mathrm{K}-12$ strain using the transposon Tn5, so that any mutations identified in our screen could be readily isolated and the mutated gene identified. In the endothelial cell assay used in this study, the rough LPS from a K-12 strain such as JM83 and smooth LPS from clinical isolates of $E$. coli have quantitatively identical stimulatory abilities (unpublished observations).

We screened 5704 individual Tn5 mutagenized isolates of E. coli JM83 for a reduced ability to stimulate endothelial cells to produce E-selectin. From this initial screen, 29 prospective mutants were identified. More precise secondary screening of these mutants identified two Tn5 mutants with significant loss in the ability to stimulate E-selectin formation on HUVEC cells. These mutants were designated BMS50F5 and BMS67C12.

As seen in Fig. 1, whole cells of the E. coli strain BMS67C12 have an $\sim 1$ to $2 \log$ reduction in their ability to stimulate HUVEC cells to produce E-selectin when compared with the parental strain JM83. LPS stimulation of both E-selectin expression and TNF $\alpha$ production has been shown to be mediated by the LPS receptor CD14 $(1,22)$. We therefore examined the ability of the mutant BMS67C12 to elicit the production of TNF $\alpha$ from human adherent monocytes. The BMS67C12 was at least $2 \operatorname{logs}$ less potent than its JM83 parent (Fig. 1).

Quantitation of fatty acid composition of whole cells, highly purified LPS and a proposed structure for the LPS from $B M S 67 C 12$. Gas chromatography of highly purified LPS revealed that LPS isolated from BMS50F5 was indistinguishable from the LPS isolated from the parent strain JM83 (Fig. 2, Table I). In contrast, LPS from the mutant BMS67C12 was clearly lacking the 14:0 myristoyl fatty acid moiety (Fig. 2, Table I). The small amount of 14:0 that can be seen in the chromatogram (Fig. 2) is probably due to phospholipid contamination as indicated by the presence of 16:0, which was also present in a less than stoichiometric amount (Fig. 2, Table I). Whole cell fatty acids and phospholipid content did not vary
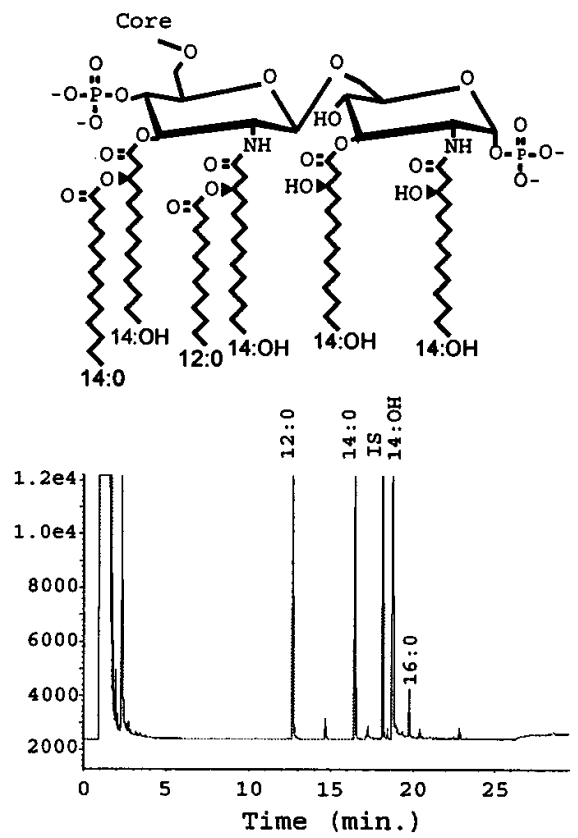
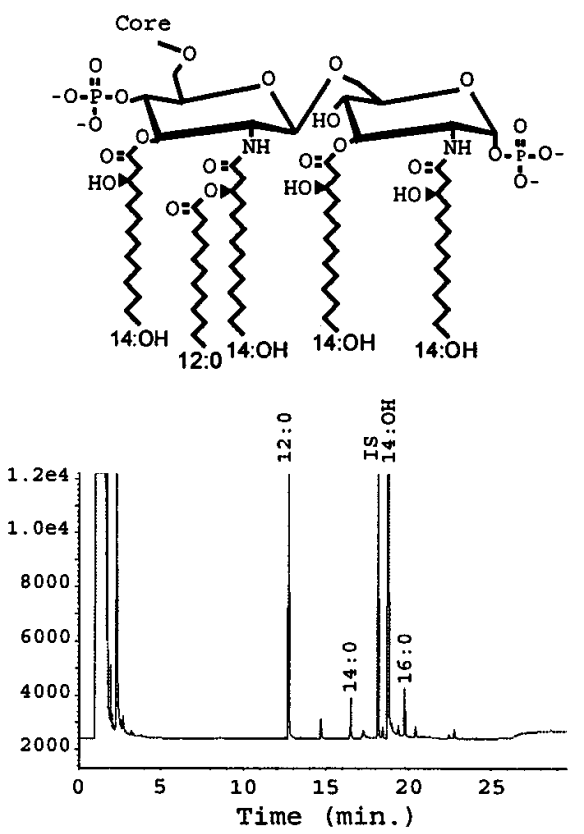

Figure 2. Fatty acid determination of purified LPS by gas chromatography (GC). GC analysis of LPS isolated from JM83 (left) and nmLPS isolated from BMS67C12 (right). The known structure of E. coli K-12 LPS (left) (5) is shown in comparison to a proposed structure for nmLPS based on the data described in Results. (12:0) dodecanoic acid/laurate; (14:0) tetradecanoic acid/myristate; (IS) internal standard of pentadecanoic acid; (14: $\mathrm{OH})$ 3-hydroxytetradecanoic acid; (16:0) hexadecanoic acid. Data shown is one of three separate determinations. 
Table I. Fatty Acid and Phospholipid Composition of E. coli Strains

\begin{tabular}{lcccccccc}
\hline & & \multicolumn{8}{c}{ Fatty acid content* $^{*}$ Strain } & $\begin{array}{c}\text { Cellular } \\
\text { component }^{*}\end{array}$ & $12: 0$ & $14: 0$ & H14:0 & $16: 1$ & $16: 0$ & $18: 1$ & $18: 0$ \\
\cline { 3 - 9 } JM83 & LPS & 2.2 & 2.2 & 6.2 & ND & 0.33 & ND & ND \\
& WC & 1.7 & 3.0 & 6.8 & 10.0 & 23.0 & 4.5 & 0.55 \\
& PL & .09 & .93 & ND & 8.7 & 17.0 & 3.5 & 0.40 \\
BMS67C12 & LPS & 2.0 & $\mathbf{0 . 3}$ & 7.2 & ND & 0.35 & ND & ND \\
& WC & 1.4 & 1.3 & 6.0 & 11.0 & 25.0 & 4.1 & 0.63 \\
& PL & 0.1 & 1.3 & ND & 8.7 & 17.0 & 2.5 & 0.36 \\
BMS50F5 & LPS & 1.3 & 1.5 & 6.4 & ND & 0.18 & ND & ND \\
& WC & 1.6 & 3.1 & 6.1 & 9.9 & 25.0 & 3.4 & 0.44 \\
& PL & .09 & .92 & ND & 6.9 & 15.0 & 2.6 & 0.40 \\
BMS67C12 & LPS & 2.6 & 2.6 & 8.7 & ND & 0.39 & ND & ND \\
(pBMS66) & WC & 1.6 & 2.3 & 7.0 & 10.0 & 27.0 & 3.5 & 0.66 \\
& PL & .07 & .84 & ND & 8.5 & 16.0 & 3.2 & 0.44 \\
& & & & & & & & \\
& & & & & & & &
\end{tabular}

* $N D$, not detected; all values are given as $\mu \mathrm{g}$ fatty acid/mg dry cell weight; (12:0) dodecanoic acid/laurate; $(14 ; 0)$ tetradecanoic acid/myristate; (H14:O) 3-hydroxytetradecanoic acid; (16:1) hexadecenoic acid; (16:1) hexadecenoic acid; (16:0) hexadecanoic acid; (18:1) octadecenoic acid; (18:0) octadecanoic acid. Data shown is one of three separate determinations. ${ }^{\ddagger} L P S$, lipopolysaccharide; $W C$, whole cells; $P L$, phospholipids.

significantly among the three strains (Table I). LPS carbohydrate as determined by trifluoracetic acid derivatization and LPS phosphate profiles of the mutants were also not significantly different from the JM83 LPS (unpublished observations). Testing of the LPS in a Limulus amebocyte lysate (LAL) assay gave values of $2.1 \times 10^{6} \mathrm{EU} / \mathrm{mg}$ for JM83 and $5.0 \times 10^{6}$ $\mathrm{EU} / \mathrm{mg}$ for BMS67C12.

In Fig. 2 the known structure of $E$. coli LPS is shown. The only significant difference we could quantitatively determine between LPS from the parental JM83 strain and LPS isolated from the BMS67C12 mutant strain was the lack of myristic acid. Based on the known E. coli LPS structure and earlier findings $(6,23)$ that indicate that the addition of myristate follows the addition of laurate in the latter steps of lipid A biosynthesis, we propose the structure shown in Fig. 2 for the demyristoylated LPS (nmLPS) from the BMS67C12 strain as the most likely. Although we do know the primary form of this LPS to be a penta-acyl structure (Kuni Takayama, personal communication), we have not yet confirmed the exact location of the laurate acyloxyacyl group.

The $n m L P S$ is responsible for the lack of stimulatory ability in mutant BMS67C12. To determine if the lack of whole cell activation of E-selectin was due primarily to the alterations identified in the nmLPS structure, the ability of purified nmLPS to stimulate HUVEC and adherent monocytes was examined. Purified nmLPS had at least a 1000 -fold reduction in its ability to stimulate E-selectin expression and was 10,000-fold less potent at the stimulation of TNF $\alpha$ from adherent monocytes (Fig. 3). Thus, the loss of inflammatory activation by the $m s b \mathrm{~B}$ mutant appears to be primarily due to the lack of myristic acid in the nmLPS.

The Tn5 insertion in mutant BMS67C12 is located in the $m s b B$ gene. It was found that both mutant strains contained

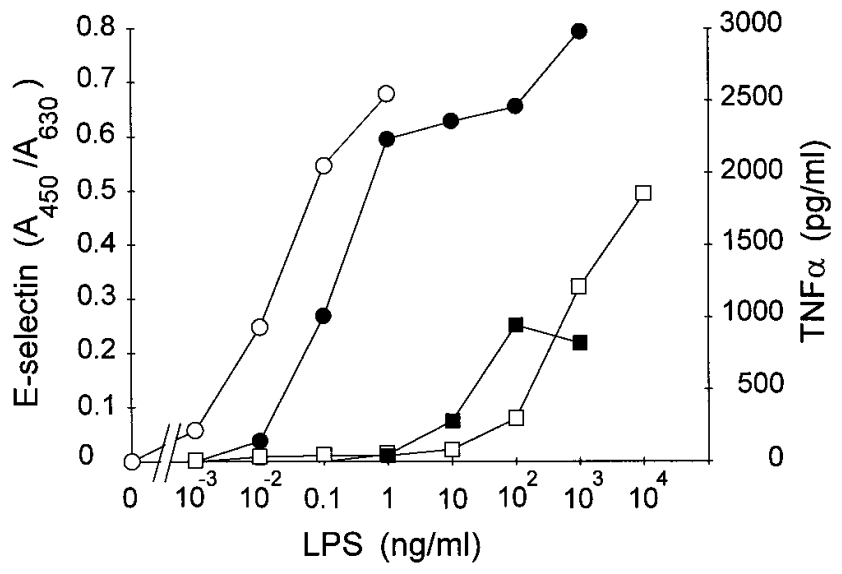

Figure 3. E-selectin expression and $\mathrm{TNF} \alpha$ production induced by purified LPS. LPS isolated from JM83 $(\bullet, \bigcirc)$ or $\operatorname{nmLPS}(\boldsymbol{\square}, \square)$ isolated from BMS67C12 were used to stimulate either HUVEC or adherent monocytes. After $4 \mathrm{~h}$ of stimulation, E-selectin expression (solid symbols) and TNF $\alpha$ (open symbols) were measured. E-selectin data shown is a representative of six separate experiments performed in duplicate and $\mathrm{TNF} \alpha$ data is a representative of three experiments performed in duplicate.

single Tn5 insertions in their chromosomal DNA. An 8.2-kb fragment was cloned into the vector plasmid pUC18 from a SacI digest of BMS67C12 total DNA. The resulting plasmid, pBMS67, was further subcloned using the single BamHI restriction site located within the Tn5 to separate the regions flanking the Tn5 insertion. DNA sequencing using a primer directed outward from each of the insertion sequence ends of the Tn5 allowed exact determination of the location of the Tn5 insertion as well as provide sequence for comparison to the GenEMBL database. The mutation in E. coli strain BMS67C12 was located in a gene previously identified as $m s b \mathrm{~B}$ (24). The $m s b \mathrm{~B}$ gene is found at $40.5 \mathrm{~min}$ on the E. coli genome and the function of its product had not been identified. The Tn5 insertion in BMS67C12 is located immediately after the glycine codon at amino acid position number 198.

$B M S 50 F 5$ is a mutation in the dsbA gene. The reduction in E-selectin expression observed for strain BMS50F5 whole cells was quite variable, could be altered by changing growth conditions and was substantially less than BMS67C12 with a maximum difference of approximately twofold (data not shown). As done with BMS67C12, an $11.1 \mathrm{~kb}$ SacI fragment was cloned from total DNA of BMS50F5 and the location of the Tn5 insertion was determined. The mutation in E. coli strain BMS50F5 is located in the gene previously identified as $d s b \mathrm{~A}(25,26)$. The $d s b \mathrm{~A}$ gene is located at $87.3 \mathrm{~min}$ on the $E$. coli genome and codes for a protein disulfide isomerase found in the periplasmic space. The Tn5 insertion in BMS50F5 is located immediately following the leucine codon at amino acid position number 111. LPS purified from BMS50F5 was found to be identical to LPS isolated from JM83 in both its composition and stimulatory abilities, so no additional studies were pursued with this strain (Table I).

The cloned msbB gene can restore the LPS structure and stimulatory phenotype to BMS67C12. The previously published sequence of $m s b \mathrm{~B}(24)$ was used to design oligonucleotide primers for the $5^{\prime}$ and $3^{\prime}$ ends of the $m s b \mathrm{~B}$ gene. These primers were then used to clone an intact copy of the $m s b \mathrm{~B}$ 


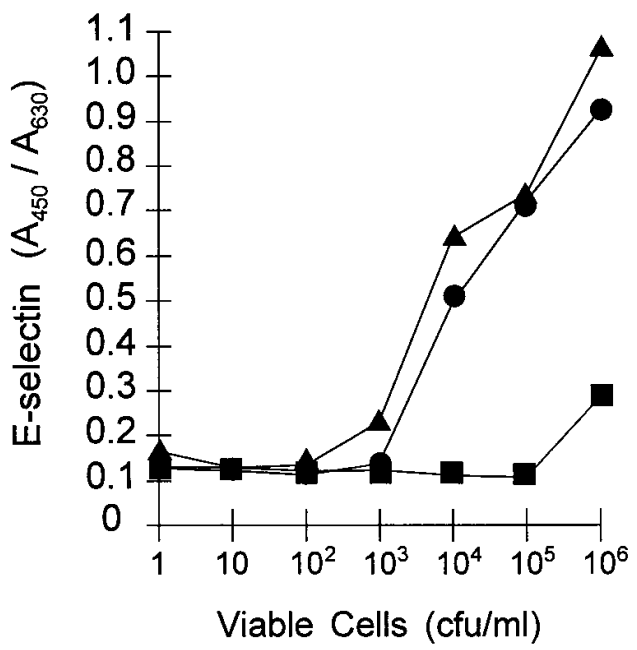

Figure 4. Phenotypic complementation of the $m s b \mathrm{~B}$ strain BMS67C12 by the plasmid pBMS66. Whole cells were prepared and used to stimulate HUVEC as described in Fig. 1. JM83 (-), BMS67C12 (घ) and BMS67C12(pBMS66) ( $\mathbf{\Delta})$. The results shown are a representative of three separate experiments.

gene using polymerase chain reaction (PCR) technology and total DNA isolated from E. coli JM83 as a template. Plasmid pBMS66 contains the isolated $m s b \mathrm{~B}$ gene, cloned into a pUC18 vector. This plasmid was transformed into BMS67C12 and tested for its ability to functionally complement the reduced stimulation phenotype. As seen in Fig. 4, when a cloned copy of the $m s b \mathrm{~B}$ gene is placed into BMS67C12, the ability of the $E$. coli cells to stimulate E-selectin expression is returned to a level comparable to that of the parental type E. coli strain. It was also found that the whole cell fatty acid, phospholipid and LPS fatty acid profiles were similar to the parental JM83 strain (Table I).

Characterization of the growth rate and antibiotic susceptibility of the msbB mutant. The earlier characterization of the $m s b \mathrm{~B}$ phenotype found no effect on cell growth (24). In this study, we also observed no difference in the growth rate of this $m s b \mathrm{~B}$ mutant when compared to the parent strain JM83 at 30 or $37^{\circ} \mathrm{C}$ (data not shown). The $m s b \mathrm{~B}$ strain BMS67C12 was also compared to JM83 for susceptibility to the detergent deoxycholate and the antibiotics rifampin, novobiocin, chloramphenicol, cefepime, and ceftazidime. With the microbroth dilution method we used, we observed no difference in the minimal inhibitory concentration (MIC) values between these two strains. These results were in contrast with an earlier report that an $m s b$ B mutant was resistant to fourfold higher levels of deoxycholate than its parental E. coli strain W3110 (>100 $\mathrm{mg} / \mathrm{ml}$ vs. $25 \mathrm{mg} / \mathrm{ml}$ ) (24). We then repeated the deoxycholate susceptibility test, but used the solid agar method in which a difference was observed (24). With this method we were able to duplicate the earlier described result (24). Differences in the methodology or media used may explain these contrasting results.

Stimulation at high concentrations of nmLPS occurs through CD14 dependent pathways. LPS stimulation of endothelial cells has been proposed to occur via a soluble form of the CD14 receptor (sCD14) $(19,22)$. In contrast, LPS stimulation of adherent monocytes (macrophages) and polymorphonuclear leukocytes is believed to occur via a membrane bound form of CD14 (mCD14) $(1,27)$. Only at relatively high doses did we see stimulation of endothelial cells or adherent monocytes by nmLPS (Figs. 1 and 4). To determine if the stimulation which was observed at the high doses required CD14, an anti-CD14 antibody (MY4) that has been shown to specifically block stimulation at CD14, was utilized (19-21). The MY4 antibody completely blocked both the nmLPS stimulation of endothelial cells and adherent monocytes as assayed by the expression of E-selectin (Fig. $5 A$ ) and the release of TNF $\alpha$ (Fig. $5 B$ ) respectively. In contrast, whole cell stimulation in both assays was only partially blocked (Fig. 5), suggesting that whole cells may interact with non-CD14 dependent pathways for E-selectin or TNF $\alpha$ activation.

$n m L P S$ can act as an antagonist to block the stimulatory action of wild type LPS. Several studies have shown that select lipid A structures or derivatives can act as antagonists for either neutrophil adhesion (4) or cytokine production (28). Accordingly, we tested if nmLPS could act as an effective com-
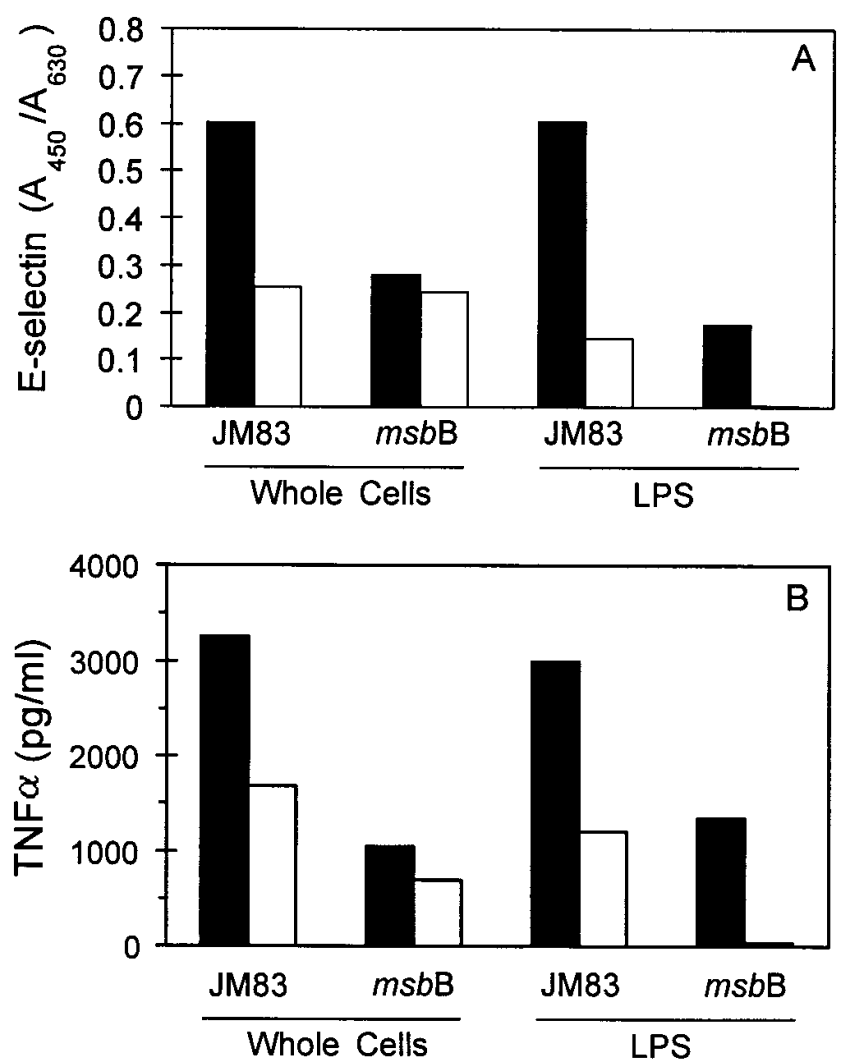

Figure 5. Inhibition of endothelial cell and monocyte activation using the antibody MY4. For HUVEC $(A)$, stimulation media with 5\% NHS was incubated for $1 \mathrm{~h}$ without antibody (solid bars) or with MY4 antibody at $10 \mu \mathrm{g} / \mathrm{ml}$ (open bars) before the addition of $1 \times 10^{5}$ whole cells, LPS (5 ng/ml) isolated from JM83 or nmLPS (500 ng/ml) isolated from BMS67C12. The stimulation mixture was placed on HUVEC for $4 \mathrm{~h}$. Cells were then assayed for E-selectin expression. In a similar experiment, adherent monocytes $(B)$ were preincubated for $1 \mathrm{~h}$ without antibody (solid bars) or with MY4 antibody at $10 \mu \mathrm{g} / \mathrm{ml}$ (open bars) in serum free RPMI1640 medium. NHS was then added to a final concentration of $5 \%$ followed by $1 \times 10^{5}$ whole cells, LPS $(10 \mathrm{ng} / \mathrm{ml})$ or $\mathrm{nmLPS}(500 \mathrm{ng} / \mathrm{ml})$. After $4 \mathrm{~h}$ of incubation the culture supernatants were assayed for TNF $\alpha$. Nonstimulated background levels of TNF $\alpha$ have been subtracted from the data shown. Each assay was performed twice with similar results. 


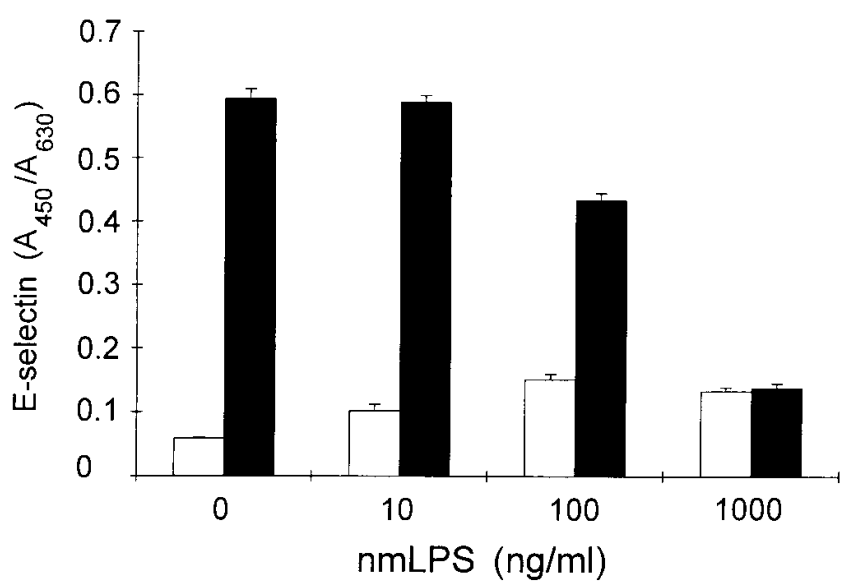

Figure 6. The ability of nmLPS to inhibit HUVEC stimulation of E-selectin expression by JM83 LPS. Varied concentrations of nmLPS with (solid bars) and without (open bars) $10 \mathrm{ng} / \mathrm{ml} \mathrm{JM} 83$ LPS were mixed together then added to HUVEC in the presence of $5 \%$ NHS. After $4 \mathrm{~h}$ of stimulation E-selectin expression was measured. The data shown is representative of two experiments done in triplicate and is presented as the mean plus one standard deviation.

petitor of JM83 LPS activation of endothelial cells to induce E-selectin expression (Fig. 6). The level of stimulation by JM83 LPS could be reduced to the level of stimulation found for nmLPS alone when provided at a ratio of between 10 and 100 (nmLPS:LPS). Additional studies were performed using smooth LPS isolated from two E. coli clinical isolates (0111B4 and A016, Seattle) with results identical to that shown in Fig. 6 for JM83 LPS.

\section{Discussion}

In this study, myristic acid has been identified as a crucial component necessary for the ability of LPS to activate immune cells. LPS that lacks myristate was significantly less able to stimulate either E-selectin expression on human endothelial cells or TNF $\alpha$ production by human adherent monocytes. This result is consistent with earlier reports that the enzymatic removal of both the myristate and laurate acyl groups from E. coli LPS results in a de-acylated LPS that has lost the ability to stimulate neutrophil adhesion (4). The structure of E. coli LPS is well known and has only one myristic acid moeity (5). We have proposed a structure for the penta-acyl LPS produced in the $m s b \mathrm{~B}$ mutant based upon the known LPS structure, the similarities in the quantified LPS fatty acid carbohydrate and phosphate profiles, the whole cell fatty acid and phospholipid profiles, and an earlier determination that addition of myristate occurs late in the lipid A biosynthetic pathway $(6,23)$. While this exact structure has yet to be confirmed, we believe that it is the most likely one that can occur.

The $m s b \mathrm{~B}$ mutation is the only non-temperature sensitive mutation thus far identified in the lipid A biosynthetic pathway, therefore it allowed us to examine the role of nmLPS when presented in the context of the intact viable bacterial cell. With the $m s b \mathrm{~B}$ mutant we found that absence of the ability to add myristate onto the lipid A conveyed a loss in stimulatory ability for intact cells that was similar to that seen with purified nmLPS. Presentation of an LPS derivative to host cells in this way helps to reduce the concern that purified LPS can form aggregates $(29,30)$. Since aggregation and micelle formation may affect the presentation of the LPS to the host cells, conclusions about the stimulatory properties of purified LPS derivatives have been guarded. Presentation of LPS during the course of an infection could take many forms and involve additional bacterial components that have yet to be identified. Our finding that the anti-CD14 antibody could only partially block the stimulatory ability of whole cells, while it could entirely block the stimulation by purified nmLPS, supports such a hypothesis.

We have identified conditions in which a mutation in the gene encoding a periplasmic disulfide isomerase $(d s b \mathrm{~A})$ could also affect the stimulatory ability of viable cells. Broezek and Raetz have described the myristoyl transferase as a membrane associated activity, although the techniques used were unable to define a precise membrane location (6). Their results offer one explanation of our results if the periplasmically located disulfide isomerase is necessary for the correct folding of the transferase. An alternative explanation also can be found if the $d s b \mathrm{~A}$ mutation has an effect on other cell factors that are involved in LPS presentation.

The data presented in this study clearly defines a role for the product of the $m s b \mathrm{~B}$ gene in the addition of myristate during the biosynthesis of the E. coli lipid A. The $m s b \mathrm{~B}$ gene was originally identified as a multicopy suppressor of a mutation in the $h t r \mathrm{~B}$ gene of $E$. coli (24). A mutation in the $h t r \mathrm{~B}$ gene results in a strain that is unable to grow above $32.5^{\circ} \mathrm{C}(31)$. It was also found that the peptides encoded by these two genes contained a significant degree of homology (24). In this study we do not present the direct evidence required to designate the $m s b \mathrm{~B}$ gene as the structural gene of the myristoyl transferase protein. However, several pieces of evidence suggest that $m s b \mathrm{~B}$ gene is a good candidate for the myristoyl transferase structural gene. First, the whole cell fatty acid profile of the $m s b \mathrm{~B}$ mutant was not significantly different than that of the parent strain. Mutation of a gene involved in general fatty acid biosynthesis might be expected to alter the whole cell fatty acid profile. We observed functional complementation of the $m s b \mathrm{~B}$ mutation when a cloned $m s b \mathrm{~B}$ gene was provided and the use of a high copy number vector also did not result in significant alterations in the fatty acid profiles of the whole cell fatty acids. The $m s b \mathrm{~B}$ mutation also had no effect on the addition of laurate. The specificity of the $m s b \mathrm{~B}$ phenotype to exclude just the myristoyl group but not the lauroyl fatty acid on the LPS, indicates that there are probably two separate enzymes involved in the addition of myristoyl and lauroyl fatty acids to the final lipid A structure. The presence of two separate enzymes for each of these functions has also been proposed previously based on biochemical data (6). In addition, our findings are supported by a recent report by Clementz et al. that identified the products of both the $m s b \mathrm{~B}$ and $h t r \mathrm{~B}$ genes as having a role in the addition of myristate and laurate respectively to the (KDO) $)_{2}$-lipid $\mathrm{IV}_{\mathrm{A}}$ of E. coli (32). Results from our own laboratory also indicate that a mutation in the $h t r \mathrm{~B}$ gene affects the addition of laurate to the lipid A (manuscript in preparation).

The nmLPS interacts through both the soluble and membrane associated forms of the CD14 receptor and is not due to stimulation through an unknown alternative receptor pathway. The ability of the MY4 antibody to block the ability of nmLPS to stimulate both endothelial cells and adherent monocytes, indicates that the stimulation seen at relatively high concentra- 
tions of nmLPS is still dependent on the CD14 receptor pathways that have been described earlier $(1,19,22)$. However, it remains unknown whether or not the antagonistic abilities of the nmLPS occurs through the CD14 receptor itself or some other component of this pathway.

Recently, a number of reports have shown that bacteria associated with chronic inflammatory disease have a naturally occurring lipid A structure that is significantly different than that of $E$. coli $(33,34)$. Often these LPSs lack or have different acyloxyacyl fatty acids that are believed to be important in host cell stimulation of inflammation $(3,4,35)$. We have shown that LPS isolated from one such bacteria is altered in its ability to stimulate components of the inflammatory response and is an antagonist for E-selectin expression (7). It is not unreasonable to suspect that these bacteria have evolved to escape detection by our innate host response system. The isolation of mutants in lipid A synthesis such as the $m s b \mathrm{~B}$ strain, in addition to producing LPS of therapeutic potential, may assist in addressing the suggestion that variations in LPS structure may facilitate persistent colonization during chronic infection (7).

\section{Acknowledgments}

We would like to thank Kent Ratcliffe for assisting with the use of the E-selectin assay as a mutant screen. LAL assays were performed by Stephen Meyer. Debby Baxter assisted in the preparation of this manuscript. We would also like to thank the oligonucleotide and DNA sequencing core facilities at Bristol-Myers Squibb, Seattle for their services.

\section{References}

1. Wright, S. D., R. A. Ramos, P. S. Tobias, R. J. Ulevitch, and J. C. Mathison. 1990. CD14, a receptor for complexes of lipopolysaccharide (LPS) and LPS binding protein. Science (Wash. DC). 249:1431-1433.

2. Morrison, D. C., R. L. Danner, C. A. Dinarello, R. S. Munford, C. Natanson, M. Pollack, J. J. Spitzer, R. J. Ulevitch, S. N. Vogel, and E. McSweegan. 1994. Bacterial endotoxins and pathogenesis of gram-negative infections: current status and future direction. J. Endotoxin Res. 1:71-83.

3. Takada, H., and S. Kotani. 1992. Structure-function relationships of lipid A. In Bacterial endotoxic lipopolysaccharides. Volume I. Molecular Biochemistry and Cellular Biology. D. C. Morrison and J. L. Ryan, editors. CRC Press, Boca Raton, FL. 107-130.

4. Pohlman, T. H., R. S. Munford, and J. M. Harlan. 1987. Deacylated lipopolysaccharide inhibits neutrophil adherence to endothelium induced by lipopolysaccharide in vitro. J. Exp. Med. 165:1393-1402.

5. Raetz, C. R. H. 1993. Bacterial endotoxins: Extraordinary lipids that activate eucaryotic signal transduction. J. Bacteriol. 175:5745-5753.

6. Brozek, K. A., and C. R. H. Raetz. 1990. Biosynthesis of lipid A in Escherichia coli. Acyl carrier protein-dependent incorporation of laurate and myristate. J. Biol. Chem. 265:15410-15417.

7. Darveau, R. P., M. D. Cunningham, T. Bailey, C. Seachord, K. Ratcliffe, B. Bainbridge, M. Dietsch, R. C. Page, and A. Aruffo. 1995. Ability of bacteria associated with chronic inflammatory disease to stimulate E-selectin expression and promote neutrophil adhesion. Infect. Immun. 63:1311-1317.

8. Yanisch-Perron, C., J. Vicira, and J. Messing. 1985. Improved M13 phage cloning vectors and host strains: nucleotide sequence of the M13mp18 and pUC19 vectors. Gene. 33:103-119.

9. de Bruijn, F. J., and J. R. Lupski. 1984. The use of transposon Tn5 mutagenesis in the rapid generation of correlated physical and genetic maps of DNA segments cloned into multicopy plasmids - a review. Gene. 27:131-149.

10. Jorgensen, R. A., S. J. Rothstein, and W. S. Reznikoff. 1979. A restriction enzyme cleavage map of $\mathrm{Tn} 5$ and location of a region encoding neomycin resistance. Mol. Gen. Genet. 177:65-72.

11. Sambrook, J., E. F. Fritsch, and T. Maniatis. 1989. Molecular cloning. A Laboratory Manual. Cold Spring Harbor Laboratory Press, Cold Spring Harbor, NY.

12. Jones, R. N., A. L. Barry, T. L. Gavan, and J. A. Washington II. 1991.
Susceptibility tests: microdilution and macrodilution broth procedures. In Manual of Clinical Microbiology. E. H. Lennette, A. Balows, W. J. Hausler Jr., and H. J. Shadomy, editors. American Society for Microbiology, Washington, D.C. 972-977.

13. Koch, A. L. 1981. Growth measurement: colony counts. In A Manual of Methods for General Bacteriology. R. N. Costilow, E. W. Nester, W. A. Wood, N. R. Krieg, and G. B. Phillips, editors. American Society for Microbiology, Washington, D.C. 185-188.

14. Westphal, O., and K. Jann. 1965. Bacterial lipopolysaccharides: extraction with phenol-water and further applications of the procedure. In Methods in Carbohydrate Chemistry. R. L. Whistler, editor. Academic Press, Inc. New York. 83-91.

15. Hanson, R. S., and J. A. Phillips. 1981. Chemical composition. In A Manual of Methods for General Bacteriology. P. Gerhardt, R. G. E. Murray, R. N. Costilow, E. W. Nester, W. A. Wood, N. R. Krieg, and G. B. Phillips, editors. American Society for Microbiology, Washington, D.C. 328-364.

16. Bryn, K., and E. Jantzen. 1982. Analysis of lipopolysaccharides by methanolysis, trifluoroacetylation, and gas chromatography on a fused-silica capillary column. J. Chromatog. 240:405-413.

17. Ames, B. N. 1966. Assay of inorganic phosphate, total phosphate and phosphatases. Methods Enzymol. 8:115-118.

18. Somerville, J. E., and M. L. Kahn. 1983. Cloning of the glutamine synthetase I gene from Rhizobium meliloti. J. Bacteriol. 156:168-176.

19. Frey, E. A., D. S. Miller, T. G. Jahr, A. Sundan, V. Bazil, T. Espevik, B. B. Finlay, and S. D. Wright. 1992. Soluble CD14 participates in the response of cells to lipopolysaccharide. J. Exp. Med. 176:1665-1671.

20. Couturier, C., N. Haeffner-Cavaillon, M. Caroff, and M. D. Kazatchkine. 1991. Binding sites for endotoxins (lipopolysaccharides) on human monocytes. J. Immunol. 147:1899-1904.

21. Lee, J.-D., V. Kravchenko, T. N. Kirkland, J. Han, N. Mackman, A. Moriarty, D. Leturcq, P. S. Tobias, and R. J. Ulevitch. 1993. Glycosyl-phosphatidylinositol-anchored or integral membrane forms of CD14 mediate identical cellular responses to endotoxin. Proc. Natl. Acad. Sci. USA. 90:9930-9934.

22. Pugin, J., C.-C. Schurer-Maly, D. Leturcq, A. Moriarty, R. J. Ulevitch, and P. S. Tobias. 1993. Lipopolysaccharide activation of human endothelial and epithelial cells is mediated by lipopolysaccharide-binding protein and soluble CD14. Proc. Natl. Acad. Sci. USA. 90:2744-2748.

23. Fischer, W. 1990. Purification and fractionation of lipopolysaccharide from gram-negative bacteria by hydrophobic interaction chromatography. Eur. J. Biochem. 194:655-661.

24. Karow, M., and C. Georgopoulos. 1992. Isolation and characterization of the Escherichia coli msbB gene, a multicopy suppressor of null mutations in the high-temperature requirement gene htrB. J. Bacteriol. 174:702-710.

25. Akiyama, Y., N. Kamitani, N. Kusukawa, and K. Ito. 1992. In vitro catalysis of oxidative folding of disulfide-bonded proteins by the Escherichia coli dsbA (ppfA) gene product. J. Biol. Chem. 267:22440-22445.

26. Bardwell, J. C. A., K. McGovern, and J. Beckwith. 1991. Identification of a protein required for disulfide bond formation in vivo. Cell. 67:581-589.

27. Wright, S. D., R. A. Ramos, A. Hermanowski-Vosatka, P. Rockwell, and P. A. Detmers. 1991. Activation of the adhesive capacity of CR3 on neutrophils by endotoxin: dependence on lipopolysaccharide binding protein and CD14. J. Exp. Med. 173:1281-1286.

28. Christ, W. J., O. Asano, A. L. C. Robidoux, M. Perez, Y. Wang, G. R. Dubuc, W. E. Gavin, L. D. Hawkins, P. D. McGuinness, M. A. Mullarkey, et al. 1995. E5531, a pure endotoxin antagonist of high potency. Science (Wash. DC). 268:80-83.

29. Vukajlovich, S. W., and D. C. Morrison. 1983. Conversion of lipopolysaccharides to molecular aggregates with reduced subunit heterogeneity: demonstration of LPS-responsiveness in "endotoxin-unresponsive" $\mathrm{C} 3 \mathrm{H} / \mathrm{HeJ}$ spenocytes. J. Immunol. 130:2804-2808.

30. Takayama, K., Z. Z. Din, P. Mukerjee, P. H. Cooke, and T. N. Kirkland 1990. Physiochemical properties of the lipopolysaccharide unit that activates B lymphocytes. J. Biol. Chem. 265:14023-14029.

31. Karow, M., O. Fayet, A. Gegielska, T. Ziegelhoffer, and C. Georgopoulos. 1991. Isolation and characterization of the Escherichia coli htrB gene, whose product is essential for bacterial viability above $33^{\circ} \mathrm{C}$ in rich media. $J$. Bacteriol. 173:741-750.

32. Clementz, T., J. Bednarski, and C. R. H. Raetz. 1995. Escherichia coli genes encoding KDO dependent acyltransferases that incorporate laurate and myristate into Lipid A. FASEB J. 9:A1311 (Abstr.)

33. Ogawa, T. 1993. Chemical structure of lipid A from Porphyromonas (Bacteroides) gingivalis lipopolysaccharide. FEBS Lett. 332:197-201.

34. Mattsby-Baltzer, I., Z. Mielniczuk, L. Larsson, K. Lindgren, and S. Goodwin. 1992. Lipid A in Helicobacter pylori. Infect Immun. 60(10):43834387.

35. Loppnow, H., H. Brade, I. Dürrbaum, C. A. Dinarello, S. Kusumoto, E. T. Rietschel, and H.-D. Flad. 1989. IL-1 induction-capacity of defined lipopolysaccharide partial structures. J. Immunol. 142:3229-3238. 